\title{
The overlooked cohort? - Improving the taught postgraduate student experience in Higher Education
}

\author{
Lisa J Coneyworth, Rachel Jessop, Pauline Maden and Gavin White \\ Division of Nutritional Sciences, Sutton Bonington Campus, University of Nottingham, \\ Leicestershire, England, LE12 5RD
}

Corresponding author: Dr Lisa J Coneyworth, Division of Nutritional Sciences, Sutton Bonington Campus, University of Nottingham, Leicestershire, LE12 5RD.

Email: lisa.coneyworth@nottingham.ac.uk

Tel: 01159516127

Lisa Coneyworth is an Assistant Professor of Nutritional Sciences and Course Director for the MSc Nutritional Sciences programme where she teaches across a number of human nutrition undergraduate and postgraduate modules. Research interests concern micronutrient deficiencies, in particular the impact of restricted diets on micronutrient status. Pedagogical interests include understanding and improving the education and experience of postgraduate taught students.

Rachel Jessop is Director of Internationalisation for the School of Biosciences at the University of Nottingham. Rachel works with staff across the school to develop and promote internationalisation, including international teaching partnerships; incoming and outgoing student and staff mobility; international student support; working with the School's Director of Research regarding developing international research collaborations; and disseminating information about international activities.

Pauline Maden is the Faculty of Science Careers and Employability Consultant at the University of Nottingham, where she leads a team of careers professionals working in partnership with academic colleagues to deliver expert careers services. Areas of expertise include career decision making, emerging careers in science and technology and the future of work.

Gavin White is an Assistant Professor of Animal Nutrition and also Course Director for the MSc programme in Animal Nutrition where he teaches across a number of modules on livestock, zoo and pet nutrition. His pedagogical research interests include gaining a better understanding of student experiences and challenges specifically with regard to the transition from undergraduate to taught postgraduate study. 


\title{
The overlooked cohort? - Improving the taught postgraduate student experience in Higher Education
}

\begin{abstract}
Taught postgraduate students in the UK have a limited timeframe for study compared with other student groups, with most full-time taught postgraduate courses requiring intense scholarship, typically over a 12-month period. Many of these students often face a number of challenges and concerns with regard to the transition from undergraduate to taught postgraduate study as they adapt to a new learning environment with a higher level of academic expectations. In this paper, we discuss the results of a new experience survey, designed to capture a holistic view of taught postgraduate student feedback beyond the traditional academic content and to also capture self-reported challenges experienced during their studies. This article also describes the development of a new collaborative support programme in response to student feedback. The programme has been designed to offer a cohesive package of workshop sessions around academic skills, personal wellbeing, support and career development. The importance of providing a targeted support framework for this specific, and often overlooked population of students within the HE sector is discussed.
\end{abstract}

Keywords: taught postgraduate, student experience, challenges, support programme

\section{Introduction}

The postgraduate taught (PGT) student population within the UK is diverse and multicultural and approximately $60 \%$ of full time PGT students in England are registered as international (nonEuropean Union), with a further $12 \%$ registered as European Union students in England (2016). This group of students begin their postgraduate level studies with a whole range of prior experiences, knowledge, cultural norms and learning styles (Brown and Holloway, 2008a; Smith and Khwaja, 2011), sometimes balancing study with external commitments such as part-time work or caring responsibilities (Tobbell et al., 2010; Heussi, 2012). All taught postgraduate students have previously been awarded an undergraduate degree and therefore have experience of learning within a higher education system, so one may assume they have familiarity with expectations of study (Heussi, 2012). However, recent research has suggested that these students (including UK nationals, international students and those progressing from an undergraduate course within the same institution) frequently experience anxieties and concerns directly related to the transition to 
postgraduate level study (Morgan and Direito, 2016; Bamber et al., 2017; Gbadamosi, 2018). Such stressors may be related to proficiency of language skills, financial constraints, personal safety in an unfamiliar environment, accommodation, culture or specifically related to their chosen course/programme (Smith and Khawaja, 2011). Unlike other programmes of study over 3 or 4 years (typically undergraduate or doctoral research), full-time postgraduate taught courses within the UK tend to be approximately 12 months in duration and are often intense in nature, which may exacerbate the challenges experienced by both home and international students (Tian and Lowe, 2013) and potentially negatively impact upon their learning experience.

The U-curve (and subsequently, the $\mathrm{W}$-curve) model of cultural adaptation has been used frequently for several years to describe the culture shock experienced mainly by international students adapting to a new learning environment (Lysgaard, 1955; Gullahorn and Gullahorn, 1963; Burnapp, 2006). This model outlines the postgraduate student journey from the exciting 'honeymoon' period followed by a period of culture shock and adjustment before a student finally adapts to their new country and learning environment approximately 10-months post arrival. Coincidently, this final adaptation typically coincides with the completion of the taught aspect of UK postgraduate degree programmes and commencement of the final research project. Research has suggested that although this generalised model may be reflective of some taught postgraduate student journeys, in reality this transition is often much more complex and unpredictable in nature (Brown and Holloway, 2008; Chien, 2016) and many students, both of home and international background, may experience a number of challenges when transitioning to postgraduate level studies within the UK (Lillyman and Bennett, 2014). Compared with undergraduate students, PGT students tend to be exposed to fewer resources designed to introduce them to the University culture including familiarisation with teaching and learning practices. An implicit assumption that these graduate students are already 'experts' due to prior experiences may be in stark contrast to the students' own 
self-identification as 'confused and struggling' (Tobbell and O'Donnell, 2013). The need to take increased responsibility for their own learning and an increased requirement for independent study means a successful postgraduate student is often required to undergo identity shifts in both personal and University practices (Tobbell et al., 2010).

The UK is the second most popular study destination of choice for both international undergraduate and postgraduate students combined (Lillyman and Bennett, 2014), with a number of factors influencing this decision including the opportunity to improve English, perceived quality provision and enhanced career prospects (Teichler, 2004; Kettle, 2011). As the number of international students in UK Universities has grown over the past 20 years, the associated income generated through fees from this student population now plays an important part in the financial health of the HE sector in the UK (Brown and Holloway, 2008a). Likewise, the provision of postgraduate loans for UK students in 2016 has been a driving force behind an observed increase in home postgraduate taught students registered within the UK (HESA, 2017). Students demonstrate a variety of motivations for taught postgraduate level study ranging from the enhancement of future employment opportunities to current career progression and personal interest (PTES, 2018). Accordingly, competition for postgraduate students has intensified (Donaldson and McNicholas, 2004) and many students are now looking beyond the traditional institutional academic reputation and are now also taking into account the support structures available to them within Universities when making a decision regarding study destination (Smith, 2006). There is an increasing need therefore for universities to gain a better understanding of this diverse cohort of postgraduate taught students and in particular focus on how their motivations, expectations and processes of adaptation and acculturation may impact their learning experience and successful transition to postgraduate level studies.

To date, there has been limited academic research evaluating the transition from undergraduate to, 
specifically, taught postgraduate study. Only through a better understanding of the challenges/anxieties associated with acculturation, and the transition to intense postgraduate study, can an effective support network be put in place to create a positive impact on the learning process of this increasingly important and growing student cohort.

This research was completed within the School of Biosciences at a leading Russell Group University in the UK. The aims of the research were to evaluate the overall experience of PGT students within the School of Biosciences, identify key challenges perceived by this student group and use these data to develop a support programme to aid the transition to postgraduate level studies.

\section{Methods}

\section{The Research Approach}

Taught postgraduate students concluding their course within the School of Biosciences during Summer 2016 were invited to complete a PGT student experience survey. All surveys used in this research were developed and distributed using the Bristol Online Surveys software and were conducted under institutional guidelines as approved in advance by the University's Research Ethics Committee. All respondents agreed that although student anonymity would be maintained, any data collected from the survey may be used for wider knowledge transfer and/or publication. Surveys were distributed online to student university email accounts and advertised via lecture shout-outs.

\section{Survey Design}

The PGT student experience survey was consciously designed to capture student views around course evaluation, but to also go beyond this traditional remit to gather wider student feedback on previous study experience and, importantly, to identify any challenges experienced by students throughout their PGT studies. Survey questions were generally divided into defined sections 
including course-specific content, infrastructure facilities and support, personal support and previous student experience and challenges. The survey contained a range of questions; several required box-ticking on a Likert scale, allowing general patterns to be identified. A box for free text was also included at the end of each section, to allow the students to expand upon any answers given, or to provide any additional information.

\section{Findings}

\section{Participants}

Of the 70 students who completed the postgraduate taught student experience survey, $70 \%$ were from an international background. Although there were a small number of exceptions, most respondents answered all survey questions.

\section{Self-reported challenges faced by Postgraduate Taught Students}

Survey results captured a range of PGT student views and challenges experienced both prior to undertaking postgraduate studies and throughout. Over $80 \%$ of international respondents identified challenges associated with adapting to new learning styles, a new learning environment and culture. In addition, approximately $50 \%$ of home respondents identified challenges associated with adapting to a new learning style and culture associated with the transition to PGT study (Figure 1).

Over $80 \%$ of students (68\% home and $92 \%$ international) self-reported that they did not understand what was expected from them as a new PGT student (Figure 1). Within this study population, prior to undertaking postgraduate study, $26 \%$ of students reported not being confident in using Virtual Learning Environments (VLEs) such as Moodle, and 17\% of respondents reported they were not familiar with a requirement to complete independent study outside of lectures and 
seminars. Disparity in the number of contact hours experienced within a previous academic environment was apparent; almost $50 \%$ of students were used to greater than 20 contact hours each week (Figure 2). A clear divide in terms of familiarity with assessment format was also reported, with over over $50 \%$ of international/EU students stating that they lacked confidence when writing essay style assessments compared to $0 \%$ of home students. In terms of feeling part of the wider student population, although many said they felt part of the campus community, $68 \%$ of students reported that they had not joined a University student society whilst undertaking their taught postgraduate study. These observations were used to inform the content of the Taught Postgraduate Support Programme.

[Insert Figure 1 here]

[Insert Figure 2 here]

\section{Postgraduate Taught Student Support Programme}

In response to the data collected and student feedback reported in the baseline 2016 student survey, a new collaborative initiative was developed between academics, placement support, professional development, the careers service and welfare support. A new 'Taught Postgraduate Support Programme' was created, bringing together a package of voluntary workshop sessions and academic seminars, plus one compulsory session on good academic practice. This new programme was specifically designed to introduce new PGT students to the University and the resources available to them, and to also aid them in their transition from undergraduate to taught postgraduate study within a UK HE environment. The support programme was deliberately extensive in content, encompassing broad themes around living and studying in the UK, academic skills, career development and personal wellbeing and support (see Table 1 for example sessions). To avoid 'information overload' during welcome week, the support programme was designed to take place 
throughout the entire academic year, with the majority of workshops and seminars timetabled during the Autumn Semester, and the main careers advice and additional signposting to further events delivered throughout the Spring Semester.

[insert table 1 here]

Support sessions were timetabled to minimise clashes with other teaching sessions as much as possible, in order to facilitate student attendance across the School. In practice, this resulted in one lunchtime session delivered per week, with a maximum duration of an hour. Sessions were advertised to students by various methods including Outlook appointments, email and announcements via the Virtual Learning Environment (VLE) - Moodle. The new support programme was launched for the start of the 2016-17 academic year and a dedicated Moodle page was created where brief introductory overviews of the forthcoming sessions were posted. All new PGT students commencing their academic study in Autumn 2016 within the School were automatically enrolled on the module, giving them information and access to the timetabled sessions and support resources.

In Summer 2017 and 2018, postgraduate students completing their courses were again invited to complete the student experience survey. In addition, a separate shorter survey was circulated; the aim of this additional evaluation was to assess the success of the new postgraduate support programme and to capture individual feedback on the sessions the students had found most useful, suggestions for additional content that they felt may be lacking, plus any other general views on the support programme itself. In total, 59 students completed the additional feedback survey about the support programme (72\% of respondents were from non-UK background) and again, most respondents answered most questions. 


\section{Evaluation of the Taught Postgraduate Support Programme}

Data showed that respondents had attended various events across the programme and survey results indicated that the programme was attended by students studying across a number of postgraduate courses within the School. Whilst it was not possible to extract the data from the survey, personal communication by staff reported that, as expected, some sessions (e.g. British culture) had a mainly international student audience, whilst others (such as revision and exam preparation, academic skills etc.) had a mixture of both UK and International students in attendance. Overall, almost $60 \%$ of respondents reported that this programme helped them adapt to the new environment and unfamiliar culture plus it helped them to better understand what was expected of them as a taught postgraduate student within the UK higher education system (Table 2). Reported reasons for not attending particular sessions included lack of awareness, or a student being of the view that a session was not relevant/useful for them. Other cited reasons for not attending sessions included part-time study, timetable clashes, and balancing work commitments around University education. When asked about which methods would most effectively advertise the programme in future, responses indicated emails, posters and lecture 'shout-outs' were the most preferable form of communication.

[insert Table 2 here]

\section{Discussion}

The current study has highlighted further the complexity of adjustment and acculturation experienced by many students transitioning to higher level taught study. Substantial differences in prior experiences, expectations and concerns/challenges of students embarking upon new postgraduate level studies have been identified. Key findings include variation in previous academic contact time (from $<10$ hours per week up to $>30$ hours per week), confidence when using a VLE; a resource central to accessing course material and study support, and familiarity with 
assessment formats. A large proportion of students (both home and international) identified challenges associated with understanding what is expected of them as a PGT student. Such observations and expectations should be further explored in order to better manage the transition to an intense period of higher-level study. These findings reflect those reported by Coates \& Dickinson (2012) and further supports the need for expectations of studying and learning within a UK institution (including expectations related to the number of contact hours) to be clearly communicated early in the academic year (Brown, 2007). These findings further support the need to explore the potential to establish similar postgraduate support programmes throughout the wider University and Higher Education providers.

The traditional U-curve adjustment hypothesis (Lysgaard, 1955) often used to describe the international postgraduate taught student experience and the common anxieties identified by students within our study arguably support this notion. However, this hypothesis has more recently been considered to be a simplistic approach and Chien (2016) discusses the complex interplay between academic, social and cultural adjustments experienced largely (but not exclusively) by international postgraduate taught students. Our study has highlighted that anxieties associated with the transition to postgraduate level studies may also be experienced by UK students in particular the ability to understand expectations of a postgraduate student. The provision of pre-arrival information on issues such as travel, accommodation, and shopping facilities for clothing and food can help the student orientate themselves when moving to a new academic environment (Brown and Holloway, 2008b; Owens and Loomes, 2010). It is anticipated that future work to develop and enhance the provision of pre-arrival information to postgraduate taught students within the School and wider university, will further address some of the concerns experienced by the PGT community highlighted in this study. 
It has been suggested that postgraduate students may be in a state of 'unconscious incompetence' when they arrive to begin their studies at a new institution (Beeler, 1991; Bamber et al, 2017). This idea suggests that whilst students are within this early 'honeymoon' period they may not be aware of the skills they require in order for them to flourish to the best of their ability throughout their postgraduate studies. They may also have a distorted perception of the levels of skills they have already developed (Morgan 2013; Bamber et al 2017). Packaged within the popular careers and employability section of the support programme is a session entitled 'Making the most of your masters'. This session is designed specifically to help students identify and develop key skills throughout their studies, with opportunities for personal development and employability skills.

Cultural differences and norms from a prior learning environment may make transition difficult; the requirement at postgraduate level to move from a more passive learning environment (with more didactic approach) to one that encourages conversation in the classroom can be challenging (Hellsten, 2002; Wong, 2004). For example, some students may be initially reluctant to question the perceived wisdom of their lecturers (Signorini et al., 2009) or be uncomfortable with critical exchange (Brown, 2007). Certainly, language use and academic writing can be a cause of frustration and difficulties in understanding for some international students (Yeh and Inose, 2003) and some may believe grammar to be the most important aspect of English language learning, which can result in retardation of their social and academic communication (Sawir, 2005). It has been reported that there can be differences in level of interest, and willingness to engage in group work among students from differing demographic backgrounds (Gatfield, 1999). Over 50\% of international and EU respondents in the current study reported they were not used to writing extended essays (>1000 words), whereas those students most familiar with this style of assessment had graduated from a UK university with an undergraduate degree. However, the intricacies of the PGT student demographics highlight the problematic approach with associating specific challenges 
to a country of origin. The distinction between home and international students may be inferred as a simplistic approach particularly as home students adjusting to PGT level studies as mature students, those with recent citizenship, those living with disabilities or from ethnic minorities may also experience similar challenges (Jones, 2017). The sessions titled 'Teaching and Learning in the UK' and 'Academic study skills' within the support programme were designed to address some of the above issues and provided an informal setting for all students to become more familiar with their new learning environment.

Although academic related content is key to the postgraduate support programme, underpinning the initiative is the drive to instil a sense of belonging in the students. The School of Biosciences is based on a rural campus and although the central University site is accessible for students, it is important that they feel integrated into the campus population. Working to develop a postgraduate community on campus through the support network aims to enhance the organic emergence of 'communities of practice' (Wegner, 1998) the success of which will be a focus for future evaluation as the programme becomes increasingly embedded. As students learn from the total environment and not just the classroom (Haigh, 2006), the support programme has increasingly been used as a platform to increase academic and social interaction by incorporating and signposting to staff and student led social events such as the Global Café. These social events encourage students to establish a shared existence that is central to the development of a sense of belonging (Brown and Holloway, 2008b) and to move beyond their 'cultural comfort zones' to meaningfully interact with students from other cultural backgrounds (O’Leary, 2018). Social gatherings and involvement in student societies is beneficial for the transition of both home and international students to postgraduate study; increasing opportunities for friendships, which in turn provides social support, and ultimately assists with their learning (Menzies and Baron, 2013). Accordingly, future developments in the support programme will continue to engage actively with both postgraduate 
social societies and the student guild.

Overall the postgraduate support programme has been positively received by students within the School of Biosciences, encouraging valuable discussion between staff and students on how the move to postgraduate level study can be facilitated. As a result, in response to student feedback, the support programme is constantly evolving in content and structure, in order to better address challenges highlighted by postgraduates within the School. With the exception of the session entitled 'good academic practice', participation in the support programme is optional. A number of communication methods have been trialled to date including e-calendar invitations, VLE shout-outs and distribution of leaflets within the graduate centre. Timetabling a convenient regular slot during term time for the support sessions has also been challenging. These recognised challenges form the basis of ongoing discussions with students to help establish the best method of communication and delivery of the support sessions.

In summary, the support programme is a new and evolving collaborative initiative developed following evaluation of the postgraduate taught student experience survey and has been designed specifically to focus on easing the move to a higher level of taught study. Early interventions have been designed to help ameliorate the transition, and encourage students to develop a sense of autonomy whilst mobilising a platform for staff to articulate expectations of postgraduate taught students. Within the support programme itself, students are provided with an opportunity to identify skills required and assess their own perceptions of the preparedness for masters level studies' (Bamber et al, 2017). Certainly, at the start of their studies, students may not understand exactly what is involved in terms of discussion, thinking and writing at postgraduate level in the UK (Todd, 1996). The support programme has become a platform to undertake this important thought 
process, reduce anxieties and nurture the development of autonomy within this increasingly important cohort of students.

\section{Declaration of conflicting interests}

The authors contributed equally to this publication and declare no potential conflicts of interest with respect to the research, authorship, and/or publication of this article.

\section{Funding}

The authors received no financial support for the research, authorship and /or publication of this article. 


\section{References}

Bamber, V., Choudhary, C.J. and Hislop, J. and Lane, J. (2017). Postgraduate taught students and preparedness for Master's level study: polishing the facets of the Master's diamond. Journal of Further and Higher Education, 43(2), 236-250.

Beeler, K. D. (1991). Graduate student adjustment to academic life: A four-stage framework. National Association of Student Personnel Administration Journal, 28(2), 163-171.

Brown, L. (2007). A consideration of the challenges involved in Supervising International Masters Students. Journal of Further and Higher Education, 31(4), 239-248.

Brown, L and Holloway, I (2008a). The adjustment journey of international postgraduate students at an English University. Journal of Research in International Education, 7(2), 232 - 249.

Brown, L and Holloway, I (2008b). The initial stage of the international sojourn: excitement or culture shock? British Journal of Guidance and Counselling, 36(1), 33-49.

Burnapp (2006). Trajectories of adjustment of international students: U-curve, learning curve, or Third Space. Intercultural Education, 17(1), 83-93.

Chien, Y-YG. (2016). After six decades: Applying the U-curve hypothesis to the adjustment of international postgraduate students. Journal of Research in International Education, 15(1), 32-51.

Coates, N. and Dickinson, J. (2012). Meeting international postgraduate student needs: a programmebased model for learning and teaching support. Innovations in Education and Teaching International. 49(3), 295-308.

Donaldson, B. and McNicholas, C. (2004). Understanding the postgraduate education market for UKbased students. A review and empirical study. International Journal of Non-profit and Voluntary Sector Marketing, 9(4), 346-360. 
Gatfield, T. (1999). Examining Student Satisfaction with Group Projects and Peer Assessment.

Assessment in Higher Education, 24(4), 365-377.

Gbadamosi, A. (2018). The anatomy of international students' acculturation in UK universities. Industry and Higher Education, 32(2), 129-138.

Gullahorn, J. T., \& Gullahorn, J. E. (1963). An extension of the U-curve hypothesis. Journal of Social Issues, 19, 33-47.

Haigh, M. (2008). Internationalism, planetary citizenship and Higher Education Inc. Compare: A journal of Comparative and International. 38(4), 427-440.

Hellsten, M. (2002). Students in transition: needs and experience of international students in Australia. Paper presented at the $16^{\text {th }}$ Australian International Education Conference, Hobart, Tasmania.

Heussi, A. (2012). Postgraduate student perceptions of the transition into postgraduate study. Student Engagement and Experience Journal, 1(3).

Higher Education Funding Council for England (HEFCE). (2016) Overview of Postgraduate Education [Online] Retrieved from http://www.hefce.ac.uk/analysis/HEinEngland/postgrad/noneu/

Higher Education Statistics Agency (HESA). (2018) First year HE student enrolments by level of study [Online] Retrieved from https://www.hesa.ac.uk/data-and-analysis/sfr247/figure-1

Jones, E. (2017). Problematising and reimagining the notion of 'international student experience'. Studies in Higher Education, 42(5), 933-943. 
Kettle, M. (2011) Academic practice as explanatory framework: reconceptualising international students' academic engagement and university teaching. Discourse: Studies in the Cultural Politics of Education, $32(1), 1-14$.

Lillyman, S. and Bennett, C. (2014). Providing a positive learning experience for international students studying at UK universities: A literature review. Journal of Research in International Education, 13(1), 63-75.

Lysgaard, S (1955) Adjustment in a foreign society: Norwegian Fulbright grantees visiting the United States. International Social Science Bulletin 7(1), 45-51

Menzies, J.L. and Baron, R. (2013). International postgraduate student transition experiences: the importance of student societies and friends. Innovations in Education and Teaching International, 51(1), 84-94.

Morgan, M. (2013). Individual Project Report. Understanding prior feedback experiences of new Postgraduate Taught (PGT) STEM Students' and their expectations and attitudes towards PGT level study at a 1992 Institution. York: Higher Education Academy: Higher Education Academy Individual Grant.

Morgan, M. and Direito, I. (2016). Widening and Sustaining Postgraduate Taught (PGT) STEM Study in the UK: A Collaborative Project. Creating Change through Understanding Expectations and Attitudes towards PGT Study, Experiences and Experiences of Post-Study Outcomes from the Perspective. Kingston Upon Thames.

O’Leary, C. (2018). Evidence to HEC - a critique. UK Council for International Student Affairs. [Online] Retrieved from https://www.ukcisa.org.uk/blog/6492/Evidence-to-HEC-\%E2\%80\%93-a-critique 
Owens, A.R. and Loomes, S.L. (2010). Managing and resourcing a program of social integration initiatives for international students: what are the benefits? Journal of Higher Education Policy and Management. 32(3), 275-290.

Rogers, C. and Smith, P. (1992). Identifying the needs of overseas students: a monitoring exercise at the University of Southampton. Journal of International Education, 3(3), 7-24.

Sawir, E. (2005). Language difficulties of international students in Australia: The effects of prior learning experience. International Education Journal, 6(5), 567-580.

Signorini, P., Wiesemes, R. and Murphy, R. (2009). Developing alternative frameworks for exploring intercultural learning: a critique of Hofstede's cultural difference model. Teaching in Higher Education, 14(3), 253-264.

Smith, A (2006). 'Improve student experience, Rammell warns'. The Guardian, 23 March.

Smith, R.A. and Khawaja, N.G. (2011). A review of the acculturation experiences of international students. International Journal of Intercultural Relations, 35(6), 699 - 713.

Teichler, U. (2004). Temporary study abroad: the life of ERASMUS students. European Journal of Education 39(4), 395-408.

Tian, M. and Lowe, J. (2013). The role of feedback in cross-cultural learning: a case study of Chinese taught postgraduate students in a UK university. Assessment and Evaluation in Higher Education, 38(5), $580-598$.

Tobbell, J. and O'Donnell, V.L. (2013). Transition to postgraduate study: postgraduate ecological systems and identity. Cambridge Journal of Education, 43(1), 123-138. 
Tobbell, J., O’Donnell, V. and Zammit, M. (2010). Exploring the transition to postgraduate study: shifting identities in interaction with communities, practice and participation. British Educational Research Journal, 36(2), 261-278.

Todd, L. (1996). Supervising overseas post-graduate students: Problem or opportunity, in McNamara, D. and Harris, R. (eds.), Quality in Higher Education for Overseas Students. London: Routledge

Waring, S. (2011). An analysis of learning levels within and between a degree and a diploma: New Zealand case study. Quality Assurance in Education, 19(4), 441-450.

Wegner, E. (1998). Communities of practice: Learning, meaning and identity. Cambridge University Press.

Wong, J.K. (2004). Are the learning styles of Asian internationals culturally or contextually based? International Education Journal, 4(4), 154-166.

Yeh, C.J. and Inose, M (2003). International students' reported English fluency, social suppory, satisfaction and social connectedness as predictors of acculturative stress. Counselling Psychology Quarterly, 16(1), 15-28. 
Figure 1. Percentage of students identifying specific challenges to some extent in the transition to taught postgraduate study $(n=68$ responses; Home students $n=25$, EU students $n=6$, International students $\mathrm{n}=37)$

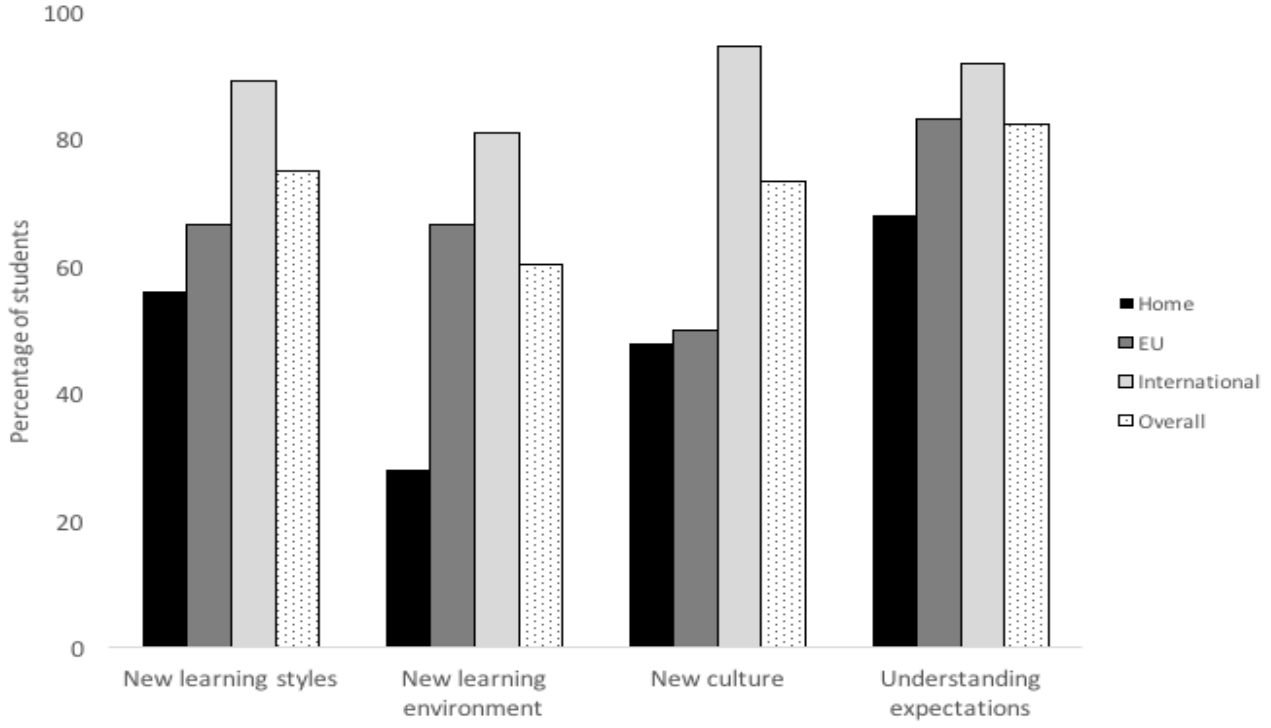

Figure 2. Prior experience of number of contact hours per week, as reported by students transitioning to taught postgraduate study ( $\mathrm{n}=69$ responses)

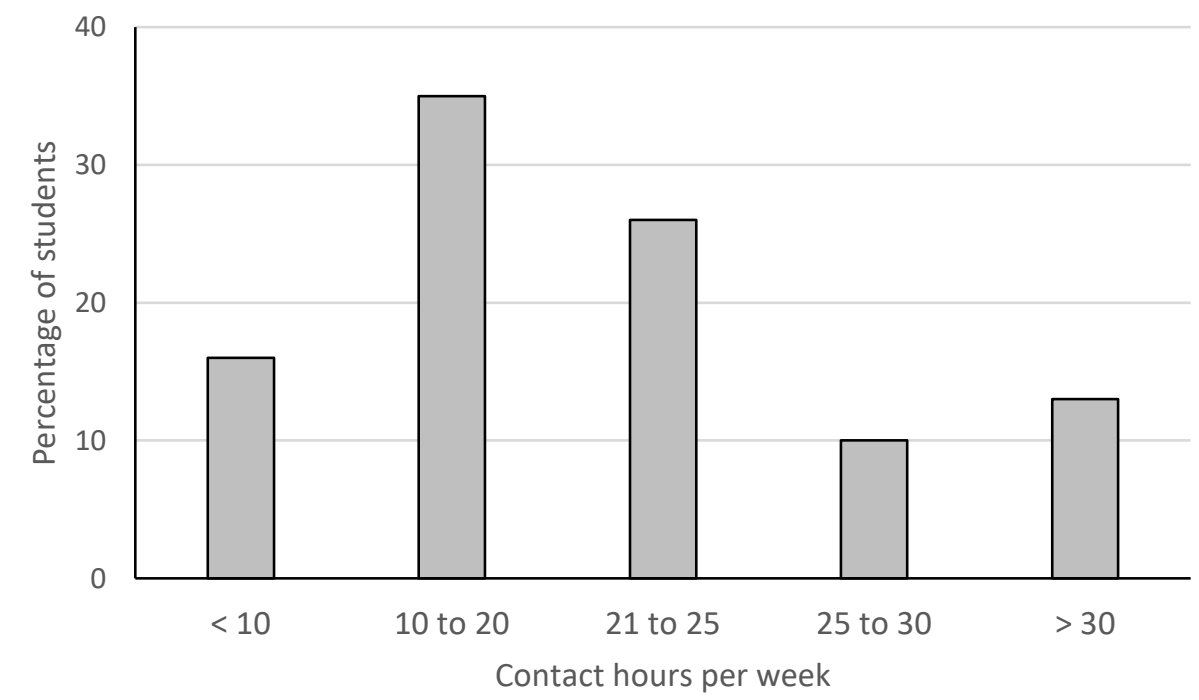


Table 1. Example sessions delivered as part of new Taught Postgraduate Support Programme

\begin{tabular}{lll}
\hline Theme & Example sessions & Overview of session \\
\hline Understanding the & $\begin{array}{l}\text { Living in the UK and British Culture } \\
\text { Teaching and Learning in the UK }\end{array}$ & $\begin{array}{l}\text { Practical information to help settle in the UK } \\
\text { Understanding expectations }\end{array}$ \\
Academic skills & $\begin{array}{l}\text { Good academic practice * } \\
\text { Understanding } \\
\text { circumstances (EC) } \\
\text { Academic study skills } \\
\text { exam preparation and revision } \\
\text { techniques }\end{array}$ & $\begin{array}{l}\text { What constitutes it and how to avoid plagiarism } \\
\text { Practical information about revision and } \\
\text { examinations }\end{array}$
\end{tabular}

Personal support and networking

Wellbeing and managing stress

Group social walks

Globe Café
Looking after your emotional and mental health A leisurely walk in the countryside Weekly social activities/events for International students

\section{Career}

development and support

Postgraduate placements

How to become employable

Developing valuable skills to enhance employability Practical information to enhance your career prospects

\section{* Compulsory}

session

Table 2. Example student feedback on the Taught Postgraduate Support Programme

\begin{tabular}{lll}
\hline Question & Code & Percentage (N) \\
\hline $\begin{array}{l}\text { The support programme helped me to adapt to a new } \\
\text { learning environment }\end{array}$ & Yes & $58(34)$ \\
& Do & $30(7)$ \\
& & $30(18)$ \\
The support programme helped me to adapt to an unfamiliar & Yes & $59(35)$ \\
culture & No & $12(7)$ \\
& Don't Know & $29(17)$ \\
The support programme helped me understand what is & & Yes \\
expected of me as a taught postgraduate student & No & 57 (33) \\
\end{tabular}

